\title{
Toluene oxidation by non-thermal plasma combined with palladium catalysts
}

\author{
Monica Magureanu ${ }^{1 *}$, Daniela Dobrin ${ }^{1}$, Nicolae B. Mandache ${ }^{1}$, Bogdan Cojocaru $^{2}$ and \\ Vasile I. Parvulescu ${ }^{2 *}$
}

1 Department for Plasma Physics and Nuclear Fusion, National Institute for Lasers, Plasma and Radiation Physics, Magurele, Bucharest, Romania

2 Department of Organic Chemistry, Biochemistry and Catalysis, University of Bucharest, Bucharest, Romania

\section{Edited by:}

Philippe Vernoux, Centre National de la Recherche Scientifique, France

\section{Reviewed by:}

Antonio De Lucas Consuegra, University of Castilla La Mancha, Spain

Elena Baranova, University of Ottawa, Canada

Xingang Li, Tianjin University, China

\section{*Correspondence.}

Monica Magureanu, Department for Plasma Physics and Nuclear Fusion,

National Institute for Lasers, Plasma and Radiation Physics, Atomistilor

Street 409, Magurele,

Bucharest 077125, Romania

e-mail:monimag@infim.ro;

Vasile I. Parvulescu, Department of

Organic Chemistry, Biochemistry

and Catalysis, Faculty of Chemistry,

University of Bucharest, Regina

Elisabeta Boulevard 4-12,

Bucharest 030016, Romania

e-mail: vasile.parvulescu@

g.unibuc.ro
The oxidation of toluene in air was investigated using a dielectric barrier discharge (DBD) combined with a $\mathrm{Pd} / \mathrm{Al}_{2} \mathrm{O}_{3}$ catalyst. When using only plasma, rather low selectivity toward $\mathrm{CO}_{2}$ was obtained: $32-35 \%$. By filling the DBD reactor with $\mathrm{Pd} / \mathrm{Al}_{2} \mathrm{O}_{3}$ catalyst the $\mathrm{CO}_{2}$ selectivity was significantly enhanced (80-90\%), however, a large amount of toluene was desorbed from the catalyst when the discharge was operated. By filling a quarter of the discharge gap with catalyst and placing the rest of the catalyst downstream of the plasma reactor, an important increase of $\mathrm{CO}_{2}$ selectivity ( $75 \%$ ) and a $15 \%$ increase in toluene conversion were achieved as compared to the results with plasma alone. The catalyst exhibited a very good stability in this reaction.

Keywords: non-thermal plasma, $\mathrm{Pd} / \mathrm{Al}_{2} \mathrm{O}_{3}$ catalyst, total oxidation of toluene, volatile organic compounds, $\mathrm{CO}_{2}$ selectivity

\section{INTRODUCTION}

The emission of volatile organic compounds (VOC) from transportation and various industrial processes represents a significant source of air pollution, and therefore VOC removal from waste gas with high efficiency and low costs is an issue of major importance for human health and the environment. Non-thermal plasma is highly efficient in producing oxidizing species (such as atomic oxygen, ozone, hydroxyl radicals, etc), which may react with the VOC molecules and decompose them, and therefore various electrical discharges have been investigated for this purpose (Leys and Morent, 2012; Magureanu, 2012). On this basis, in the last years various non-thermal plasmas, such as microwave (Horikoshi et al., 2007), corona (Van Durme et al., 2009) dielectric barrier discharge (DBD), gliding arc (Yang et al., 2009), glow discharge (Zhang et al., 2012) have been widely investigated for the total oxidation of hydrocarbons in air.

However, plasma activation is rather non-selective, so in order to obtain simultaneously high conversion and high selectivity toward total oxidation, the combination of plasma and catalysis appears more promising (Delagrange et al., 2006; Van Durme et al., 2008; Magureanu et al., 2011). Noble metal catalysts (Pd, Pt, $\mathrm{Au}, \mathrm{Ag}$ ) in combination with plasma were tested in many works, due to their high efficiency for VOCs abatement (Harling et al., 2007; Kim et al., 2008; Van Durme et al., 2009). In particular, palladium-based catalysts are well known to be among the most active catalysts for the catalytic total oxidation of methane (Zhu et al., 2004; Huang et al., 2008).

Experiments carried out using plasma also confirmed the superiority of palladium (Yamamoto et al., 2009; Kroker et al., 2012). Loading of palladium is a very important parameter and recent studies demonstrated that concentrations around $2 \mathrm{wt} \%$ provided the most effective catalysts (Da Costa et al., 2008).

In this work the total oxidation of toluene in air by plasmaassisted catalysis was investigated at room temperature and atmospheric pressure. Non-thermal plasma was generated in a DBD. A palladium catalyst supported on $\gamma-\mathrm{Al}_{2} \mathrm{O}_{3}$ was used in the experiments. Compared to previous reports this study followed a different route in the preparation of the catalyst trying to answer additional questions like: how susceptible is the palladium catalyst to the type of the precursor and to the textural properties of alumina. For this purpose, this study considered $\mathrm{PdCl}_{2}$ as precursor and alumina prepared via a route close to that reported by Da Costa et al. (2008) but with a different texture. The catalysts were placed (i) inside the plasma region (in-plasma configuration), (ii) downstream of the plasma reactor (post-plasma configuration), and (iii) both inside and after the plasma reactor (combined configuration). The effect of applied voltage, or implicitly of the discharge power, was investigated. The results 
obtained with plasma alone were compared with those achieved in the plasma-catalytic systems.

\section{MATERIALS AND METHODS MATERIALS}

The catalysts were prepared by incipient wetness impregnation of $\gamma-\mathrm{Al}_{2} \mathrm{O}_{3}$ with an acid solution of $\mathrm{PdCl}_{2}$ (ReagentPlus ${ }^{\circledR}, 99 \%$, from Sigma-Aldrich) then dried after a program of temperatures at $110^{\circ} \mathrm{C}$, calcined at $500^{\circ} \mathrm{C}$ for $2 \mathrm{~h}$ and reduced in hydrogen flow at $400^{\circ} \mathrm{C}$ for $4 \mathrm{~h}$ (Pârvulescu et al., 1994). Palladium concentration in the catalysts was $2 \%$.

\section{EXPERIMENTAL SET-UP AND PROCEDURES}

The plasma reactor consisted in a quartz tube with the inner diameter of $9 \mathrm{~mm}$. The inner electrode was a metallic rod of $3 \mathrm{~mm}$ diameter placed on the axis of the DBD reactor. The outer electrode was aluminum tape placed on the outside of the tube on a length of $48 \mathrm{~mm}$.

The discharge was operated in ac mode, with sinusoidal voltage, at $50 \mathrm{~Hz}$ frequency. The electrical circuit is described in detail in (Magureanu et al., 2011). The high voltage was applied to the inner electrode, while the outer electrode was grounded. The discharge voltage was measured by a high voltage probe (Tektronix P6015). The discharge current was determined from the voltage drop across a shunt resistor $(\mathrm{Rs}=3 \Omega$ ) connected in series with the earthed electrode. The total charge dissipated in the discharge was measured with a non-inductive capacitor $(\mathrm{C}=1 \mu \mathrm{F})$, placed instead of the shunt resistor. The discharge voltage, current and total charge were monitored by a digital oscilloscope (Tektronix TDS 2022). The amplitude of the applied voltage was varied in the range $10-20 \mathrm{kV}$. The experimental data were scaled to the specific input energy (SIE), defined as the ratio of the power and flow rate. Ambient air was used as working gas, the total gas flow rate was $163 \mathrm{~mL} / \mathrm{min}$ and the initial toluene concentration was $50 \mathrm{ppm}$.

The concentrations of $\mathrm{CO}_{2}$ and $\mathrm{CO}$ resulting from toluene oxidation were monitored continuously by a gas analyzer (Ultramat 6, Siemens) coupled on-line. Hydrocarbons and oxidation byproducts were analyzed on a HP 5890 Series II Gas Chromatograph equipped with a TCD detector. Prior analysis, reactants and by-products were separated on a Porapaq Q column. The concentration of ozone in the effluent gas was measured by an ozone analyzer (Ozomat MP, Anseros).

\section{CHARACTERIZATION MEASUREMENTS}

The catalysts were characterized using elemental analysis, differential thermal and thermogravimetric analysis, adsorptiondesorption isotherms at $-196^{\circ} \mathrm{C}, \mathrm{XRD}, \mathrm{DRIFTs}$, and TEM. The differential thermal and thermogravimetric analysis was carried out using a TG-DTA analyzer (Shimadzu DTG-60 Simultaneous DTA-TG Apparatus) on 4-6 mg samples in nitrogen atmosphere under the heating rate of $10^{\circ} \mathrm{C} / \mathrm{min}$ from room temperature to $900^{\circ} \mathrm{C}$ and using alumina as reference. The $\mathrm{C}, \mathrm{N}$, and $\mathrm{S}$ content of the samples was determined using a EuroVector Euro EA Elemental Analyzer (combustion elemental analyzer). X-Ray diffraction patterns were recorded using a Shimadzu XRD-7000 diffractometer with $\mathrm{Cu} K \alpha(\lambda=1.5418 \AA, 40 \mathrm{kV}, 40 \mathrm{~mA})$ at a step of $0.02^{\circ}$ and a scan rate of $2^{\circ} / \mathrm{min}$ in the $2 \theta$ range of $5-90^{\circ}$. Crystalline phase were identified by comparasion of the XRD patterns with the JCPDS database. FTIR spectra were recorded at room temperature in nitrogen atmosphere with a Thermo Electron Nicolet 4700 spectrometer using a diffuse reflectance (DR) accessory (Smart Collector for DRIFT spectra). The final spectra correspond to an average of 100 scans with $4 \mathrm{~cm}^{-1}$ resolution. TEM analysis characterizations were carried out using a JEOL JEM-1010 instrument operating at $100 \mathrm{kV}$ and equipped with a CCD camera and a Tecnai $\mathrm{G}^{2} \mathrm{~F} 20$ (FI) instrument, respectively.

\section{RESULTS}

\section{DISCHARGE CHARACTERISTICS}

The discharge has a filamentary nature, typical for DBDs at atmospheric pressure, consisting in a multitude of plasma filaments of short duration (tens of ns). As previously mentioned, the voltage is sinusoidal and the current consists of several peaks with amplitudes of tens to hundreds of $\mathrm{mA}$ and durations of tens of nanoseconds on each alternance of the voltage. The electrical power dissipated in the discharge was calculated by the Lissajous method (Falkenstein and Coogan, 1997). Figure 1 shows the SIE as a function of the amplitude of the applied voltage. The SIE depends approximately linearly on the voltage. When increasing the applied voltage from 10 to $20 \mathrm{kV}$, the average power increased from 0.16 to $0.88 \mathrm{~W}$ and the SIE varies in the range 59-324 J/L. Since the power is very low, thermal effect can be excluded. The formation of nitrogen oxides is also avoided at these low values of discharge power.

\section{TOTAL OXIDATION OF TOLUENE}

Figure 2 shows toluene conversion and the selectivity to carbon dioxide and carbon monoxide as a function of SIE for the experiments performed in plasma, in the absence of catalysts. The conversion of toluene in plasma was $8 \%$ for the lowest input energy used and reached $48 \%$ for highest SIE. The only gaseous reaction products of toluene oxidation in the plasma were $\mathrm{CO}$ and

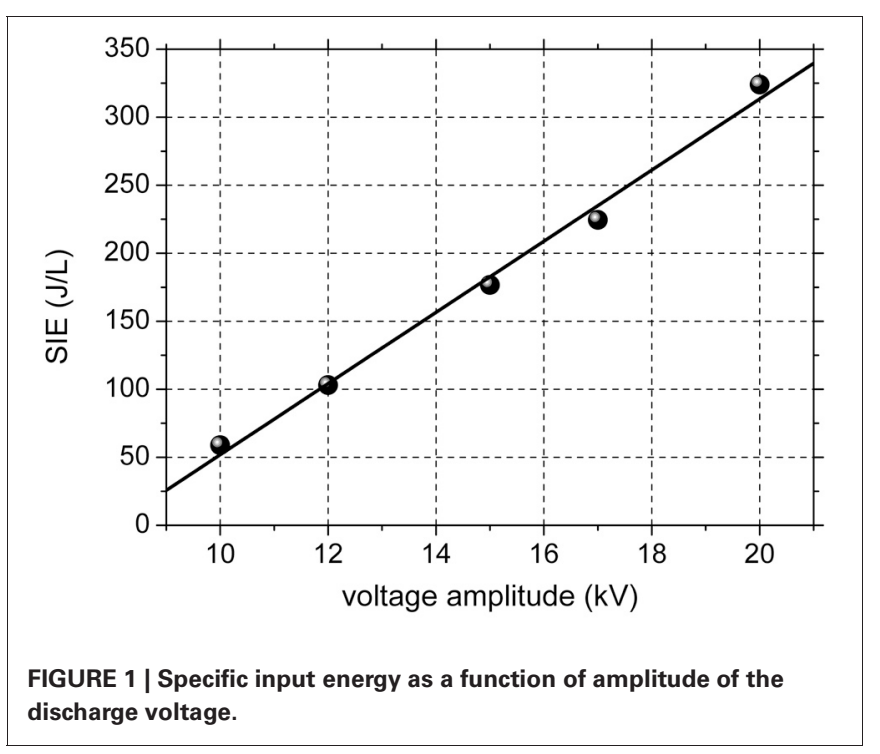




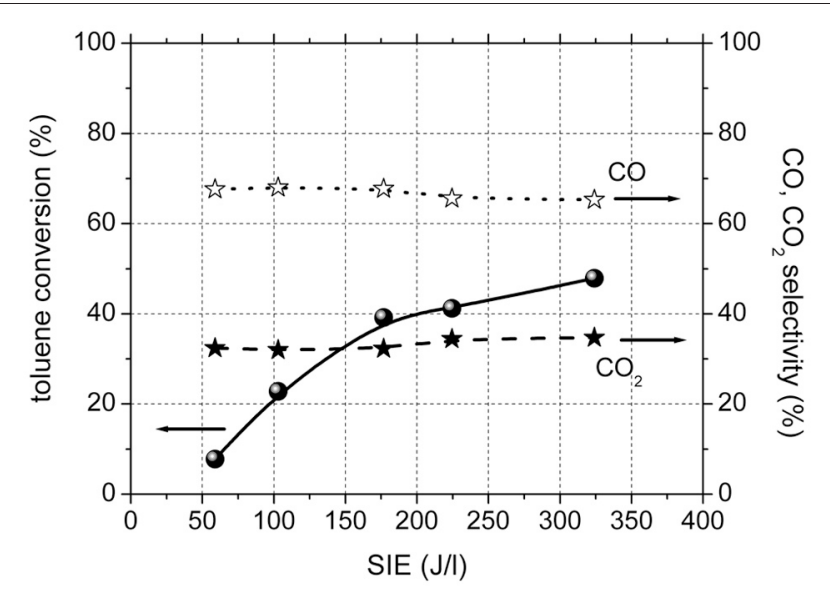

FIGURE 2 | Toluene conversion and $\mathrm{CO}$ and $\mathrm{CO} 2$ selectivity in DBD in the absence of catalysts.

$\mathrm{CO}_{2}$. The selectivity to $\mathrm{CO}_{2}$ showed a very slight increase with SIE and ranged between 32 and $35 \%$.

In a first set of experiments $2.24 \mathrm{~g}$ catalyst were introduced in the DBD reactor, occupying the entire discharge gap. Initially, the gas was passed through the reactor for several hours with plasma off, so that toluene was adsorbed on the catalyst bed until saturation was reached. After the plasma was turned on, a large amount of toluene was desorbed from the catalyst. Therefore, a much higher toluene concentration is actually present in the plasmacatalytic reactor as compared to the input concentration. Since it is well known that conversion decreases with increasing concentration, poorer toluene conversion as compared to that obtained in the DBD is expected. Indeed, toluene conversion is considerably lower than the above-mentioned values, remaining below $10 \%$ even at the highest SIE used. Although an important part of the toluene was converted mainly into $\mathrm{CO}_{2}$ (selectivity $80-90 \%$, see Figure 3), the effluent gas still contained a high concentration of toluene, therefore this configuration was not effective for total toluene removal.

In the following experiments only $0.56 \mathrm{~g}$ of catalyst were placed in the discharge region. In this case the toluene conversion was similar with that obtained with plasma alone. The amount of toluene removed is actually higher, because part of the toluene adsorbed on the catalyst is also oxidized. This is evidenced also by the concentration of carbon oxides $\left(\mathrm{CO}+\mathrm{CO}_{2}\right)$ in the effluent gas, which increased significantly (with 40-70\%) as compared to the results obtained with plasma alone, due to conversion of adsorbed toluene. The selectivity to $\mathrm{CO}_{2}$ was $76-77 \%$ regardless of SIE. Clearly, the presence of $\mathrm{Pd} / \mathrm{Al}_{2} \mathrm{O}_{3}$ catalysts significantly improved the process selectivity toward total oxidation.

Another experiment was performed with $0.56 \mathrm{~g}$ catalyst placed inside the discharge area and $1.7 \mathrm{~g}$ catalyst placed downstream of the plasma reactor. This experiment was carried out for an amplitude of the applied voltage of $17 \mathrm{kV}$, corresponding to a SIE of $225 \mathrm{~J} / \mathrm{L}$. The temporal evolution of toluene conversion and $\mathrm{CO}_{2}$ and $\mathrm{CO}$ concentrations is shown in Figure 4. The conversion showed an initial decrease of about $15 \%$ and then became stable

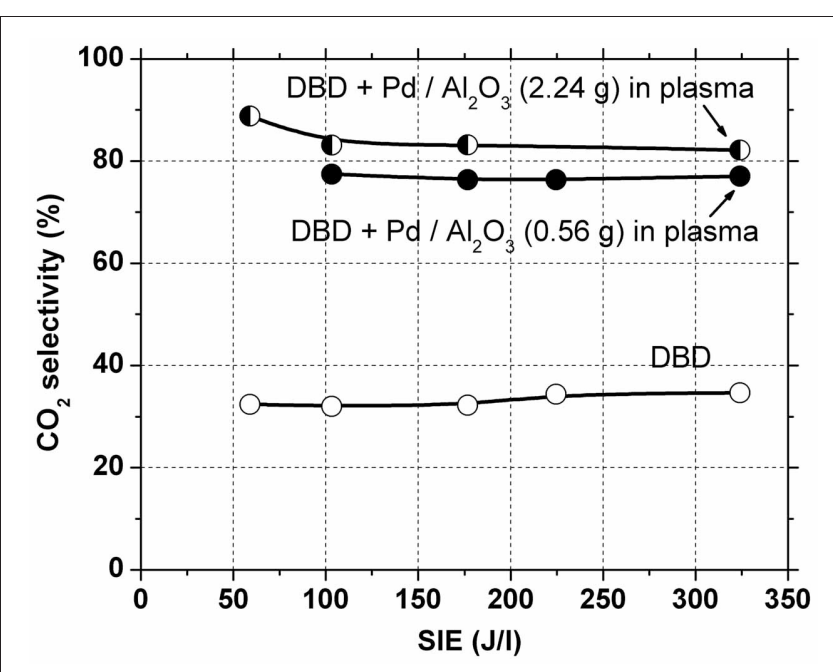

FIGURE 3 | $\mathrm{CO}_{2}$ selectivity as a function of SIE in the plasma and in the plasma-catalytic system.

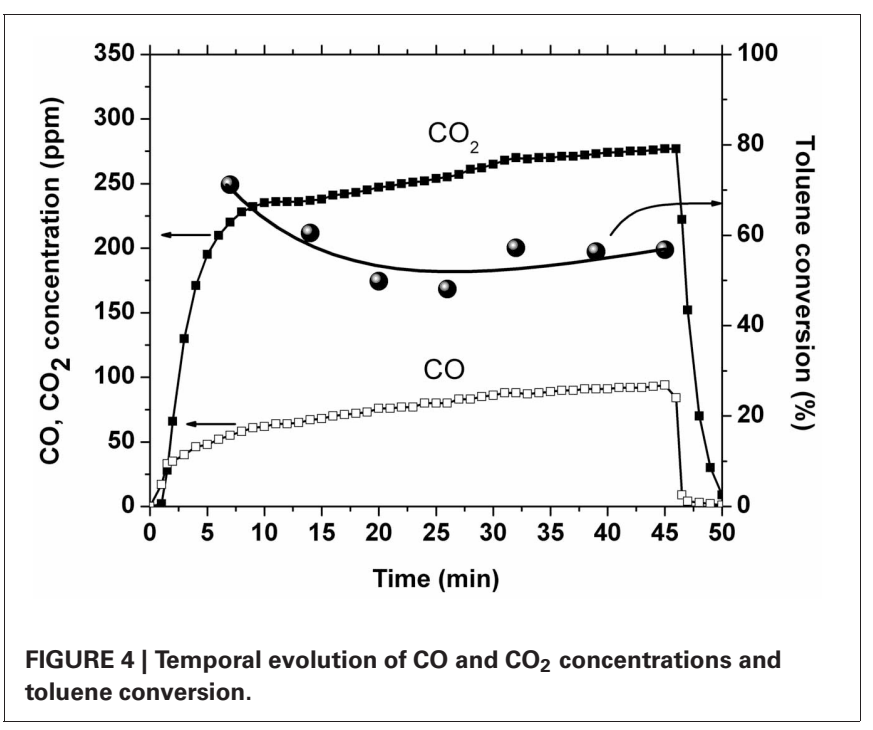

around 56\%, which represents an improvement as compared to the result obtained with plasma alone: $41 \%$ at the same SIE. The $\mathrm{CO}_{2}$ selectivity showed also a slight decrease in time, from 80 to $75 \%$, but is still largely enhanced as compared to $35 \%$ in plasma. Initially the carbon balance is very close to $100 \%$, while after several minutes of plasma operation the concentration of carbon oxides exceeds considerably the theoretical value. This behavior, together with the conversion decrease are most likely due also to the desorption of toluene from the catalyst. Even after the conversion stabilizes, the concentration of $\mathrm{COx}$ is almost two times higher than the maximum possible value, which suggests that the amount of oxidized toluene is actually higher than the $50 \mathrm{ppm}$ introduced. Therefore, plasma and ozone generated in the DBD have the ability to oxidize toluene on the catalyst surface.

A further advantage of using this configuration is the complete removal of ozone in the effluent gas. Figure 5 shows the ozone concentration generated in the DBD in the absence of catalysts, 


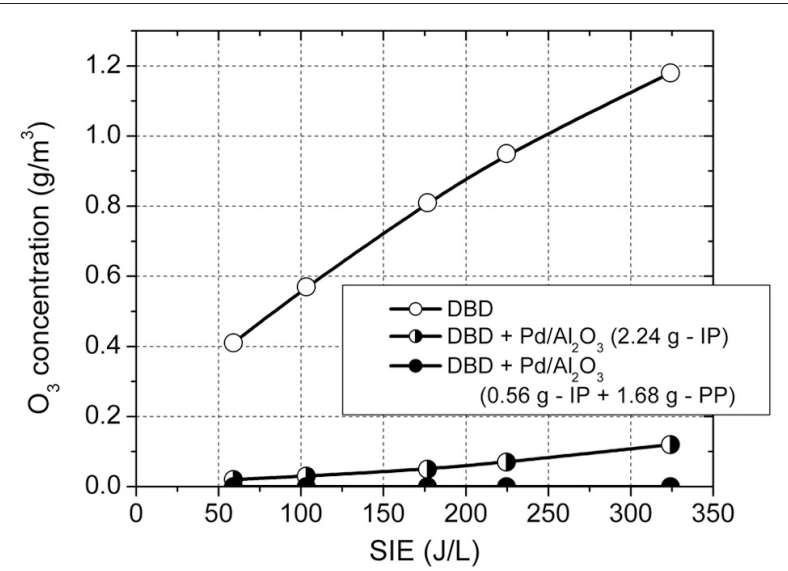

FIGURE 5 | Concentration of ozone in DBD and in the plasma catalytic system.

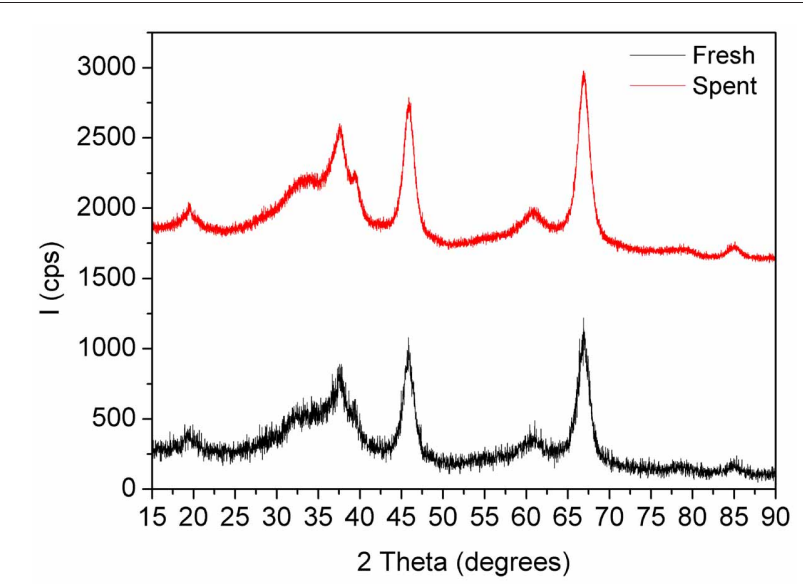

FIGURE 6 | XRD patterns of the fresh and spent $\mathrm{Pd} / \gamma-\mathrm{Al}_{2} \mathrm{O}_{3}$ catalyst. Spent catalyst was collected from inside the plasma reactor.

with the plasma reactor fully packed with catalyst and with $0.56 \mathrm{~g}$ catalyst placed in plasma and the rest ( $1.68 \mathrm{~g})$ placed post-plasma. In plasma, in the absence of catalysts, the $\mathrm{O}_{3}$ concentration increased with increasing SIE in the range $0.4-1.18 \mathrm{~g} / \mathrm{m}^{3}$. The $\mathrm{O}_{3}$ concentration was reduced to $0.02-0.12 \mathrm{~g} / \mathrm{m}^{3}$ with $2.24 \mathrm{~g}$ of catalyst introduced in the plasma zone and was completely removed when the catalyst was placed in the combined in-plasma-postplasma configuration. It is therefore obvious that ozone generated in the plasma plays an important role in toluene oxidation. The most likely mechanism is ozone decomposition on the catalyst surface, forming highly reactive atomic oxygen, which reacts with toluene and also shifts the product distribution toward total oxidation.

\section{CATALYSTS CHARACTERIZATION}

Figures 6-9 present results using spent catalysts collected from inside the plasma reactor. However, similar characterizations were obtained with catalysts inside the plasma, downstream of plasma reactor and both inside and after the reactor.

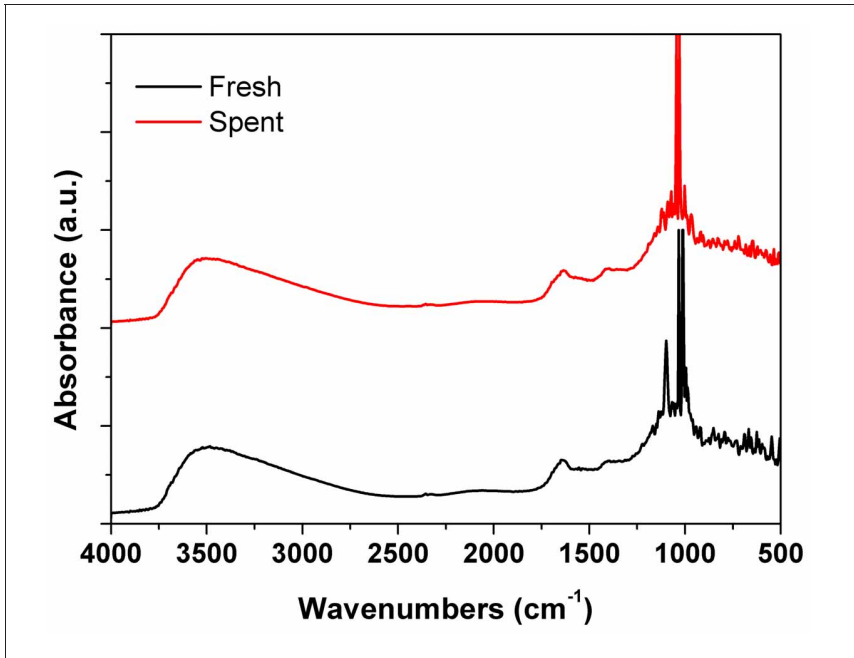

FIGURE 7 | DRIFTs spectra of the fresh and spent $\mathrm{Pd} / \gamma-\mathrm{Al}_{2} \mathrm{O}_{3}$ catalyst. Spent catalyst was collected from inside the plasma reactor.

$\mathrm{X}$-Ray diffractograms of the fresh and spent catalysts showed only diffraction planes of $\gamma-\mathrm{Al}_{2} \mathrm{O}_{3}$ with reflections located at $2 \Theta$ $19.4^{\circ}(111), 32.5^{\circ}(220), 37.48^{\circ}(011), 39.3^{\circ}(222), 45.8^{\circ}(400)$, $60.7(511), 66.9^{\circ}(440)$, and $84.8^{\circ}$ (444) respectively (PDF Card 00-050-0741) (Figure 6). None of them exhibited diffraction lines associated with palladium that accounts firstly for the good dispersion of the metal, with a particle size under the detection limit of XRD technique, and secondly for the fact that working under plasma irradiation for more than $24 \mathrm{~h}$ induced no agglomeration.

DRIFTs spectra provided additional arguments concerning the stability of the catalyst under the reaction conditions (Figure 7). The strong broadening at $3800-3000 \mathrm{~cm}^{-1}$, with a maximum around $3500 \mathrm{~cm}^{-1}$ occurs due the $\mathrm{OH}$ groups bending vibration. This band is accompanied by a band at about $1640 \mathrm{~cm}^{-1}$ which is assigned to the stretching vibration in the absorbed and coordinated water. The stronger broadening band at $1000-500 \mathrm{~cm}^{-1}$ corresponds to Al-O vibration. The band at $\sim 1092 \mathrm{~cm}^{-1}$ is assigned to Al-OH symmetric bending, the band at $\sim 1170 \mathrm{~cm}^{-1}$ is assigned to $\mathrm{Al}-\mathrm{OH}$ asymmetric bending and the band at $\sim 1396 \mathrm{~cm}^{-1}$ is assigned to Al-OH stretching. Working under plasma did not affected the presence of the $\mathrm{OH}$ groups, but only induced a decrease of the intensity of these bands that was caused by the deposition of a small amounts of carbonaceous deposits. Thermal analysis was not able to clearly detect the presence of these deposits neither from the TGA nor from the DTA profiles (Figure 8). However, elemental analysis of the fresh and spent samples identified, indeed, small amounts of carbon on the spent catalyst (Table 1). While it showed no difference in the nitrogen and sulfur content, a very slight increase in the carbon content was detected that is typical for radicalic processes where a polycondensation of the aromatic ring can occur.

TEM pictures of the fresh and spent catalyst also reveal that the exposure to the reaction conditions described above did not generate changes in the morphology of palladium (Figure 9). Fresh catalysts exposed Pd particles with sizes in the range $4.7-10 \mathrm{~nm}$, and an average size of $6.5 \mathrm{~nm}$ (Figure 9A). 


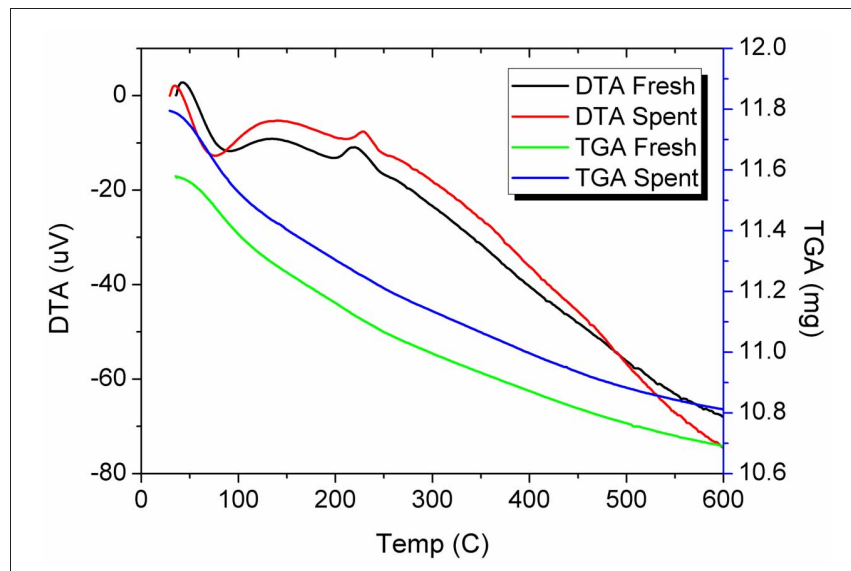

FIGURE 8 | TGA and DTA profiles of the fresh and spent $\mathrm{Pd} / \gamma-\mathrm{Al}_{2} \mathrm{O}_{3}$ catalyst. Spent catalyst was collected from inside the plasma reactor.

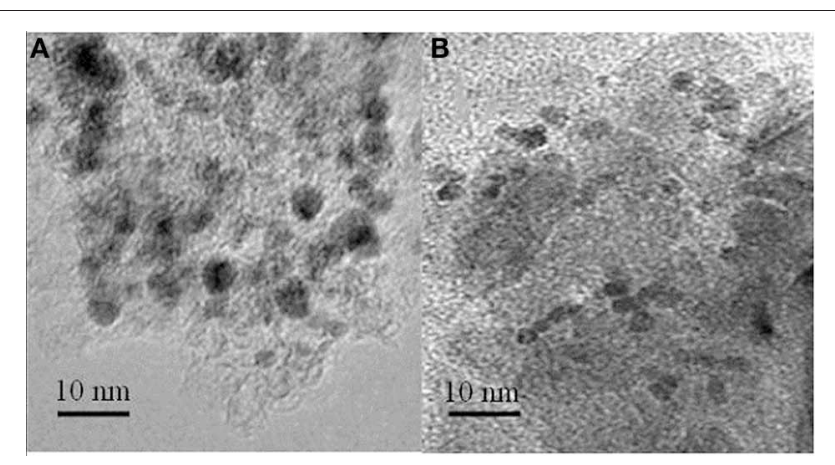

FIGURE 9 | TEM pictures of the $\mathrm{Pd} / \gamma-\mathrm{Al}_{2} \mathrm{O}_{3}$ catalyst: before (A), and after (B) the plasma/catalytic test. Spent catalyst was collected from inside the plasma reactor.

Spent catalysts exposed Pd particles with sizes in a narrower range $3.8-7.1 \mathrm{~nm}$, and an average size of $5.1 \mathrm{~nm}$ (Figure 9B). Accordingly these measurements suggest only a redispersion of the large particles.

\section{DISCUSSION}

The efficiency of a plasma-catalyst hybrid system has already been demonstrated by other studies (Magureanu et al., 2005, 2006, 2007) and the present results provide additional confirmation of such a behavior. However, up to date no clear evidence of the stability of the catalyst has been provided in the literature.

\section{REFERENCES}

Da Costa, P., Marques, R., and Da Costa, S. (2008). Plasma catalytic oxidation of methane on aluminasupported noble metal catalysts. Appl. Catal. B Environ. 84, 214-222. doi: 10.1016/j.apcatb.2008.04.013

Delagrange, S., Pinard, L., and Tatibouet, J.-M. (2006). Combination of a non-thermal plasma and a catalyst for toluene removal from air: Manganese based oxide catalysts. Appl. Catal. B Environ. 68, 92-98 doi: 10.1016/j.apcatb.2006.07.002

Falkenstein, Z., and Coogan, J. J. (1997). Microdischarge behaviour in the silent discharge of nitrogen - oxygen and water - air mixtures. J. Phys. D Appl. Phys. 30, 817. doi: 10.1088/0022-3727/30/5/015

Harling, A. M., Kim, H.-H., Futamura, S., and Whitehead, J. C. (2007). Temperature dependence of plasma

Table 1 | Elemental analysis of fresh and spent catalyst.

\begin{tabular}{llllr}
\hline Sample & \multicolumn{4}{c}{ Content, wt \% } \\
\cline { 2 - 5 } & $\mathbf{N}$ & $\mathbf{C}$ & $\mathbf{H}$ & $\mathbf{S}$ \\
\hline Fresh $\mathrm{Pd} / \gamma-\mathrm{Al}_{2} \mathrm{O}_{3}$ catalyst & 0.048 & 0.339 & 0.886 & - \\
Spent $\mathrm{Pd} / \gamma-\mathrm{Al}_{2} \mathrm{O}_{3}$ catalyst & 0.050 & 0.539 & 0.888 & - \\
\hline
\end{tabular}

Our studies demonstrate that the investigated catalyst was not affected by the plasma conditions or by a deposition of soot. Except a very small change in the intensity of the $\mathrm{OH}$ bonds belonging to the support no other changes have been evidenced. These results are well correlated to the catalysts characterization. The presence of small palladium particles limited a redispersion of the metal during the plasma-catalytic oxidation of toluene and conserved the catalytic behavior with a good stability.

Numerous studies have shown that the formation of free radicals or ion-radicals is the first and decisive stage for the non-oxidative conversion of hydrocarbons in non-equilibrium plasmas (Schmidt-Szałowski et al., 2011). Obviously, the radicalic pathway, in addition to the oxidation of the hydrocarbon, is also matter of polymerization of small derived entities with the formation of large polyaromatic structures, namely, soot. The extremely small amount of deposited carbon (see Table 1) demonstrated that for the concentration of VOC and SIE used in this study the cooperative plasma/catalytic oxidation of the toluene and derived entities occurred to a large extent.

\section{CONCLUDING REMARKS}

The results collected in this study confirmed the efficiency of $\mathrm{Pd} / \gamma-\mathrm{Al}_{2} \mathrm{O}_{3}$, not only as an active oxidation catalyst for the combustion of the hydrocarbons, but also as an efficient catalyst in a hybrid configuration with non-thermal plasma. In addition, the characterization results using elemental and thermal analysis, XRD, and DRIFT provided evidence about the stability of this catalyst under the investigated conditions. Noteworthy, these characterizations evidenced the formation of soot only in a very small amount that is also in agreement with previous reports (Holzer et al., 2002).

\section{ACKNOWLEDGMENTS}

This work was supported by a grant of the Romanian National Authority for Scientific Research, CNCS-UEFISCDI, project number PN-II-RU-TE-2011-3-0015 and by project PN 09390301.

catalysis using a nonthermal, atmospheric pressure packed bed; the destruction of benzene and toluene. J. Phys. Chem. C 111, 5090-5095. doi: 10.1021/jp067821w

Holzer, F., Roland, U., and Kopinke, F. D. (2002). Combination of non-thermal plasma and heterogeneous catalysis for oxidation of volatile organic compounds: Part 1. Accessibility of the intra-particle volume. Appl.
Catal. B Environ. 38, 163-181. doi: $\quad 10.1016 /$ S0926-3373(02) 00040-1

Horikoshi, S., Kajitani, M., Sato, S., and Serpone, N. (2007). A novel environmental risk-free microwave discharge electrodeless lamp (MDEL) in advanced oxidation processes. Degradation of the 2, 4-D herbicide. J. Photoch. Photobio. A Chem. 189, 355-363. doi: 10.1016/j.jphotochem.2007.02.027 
Huang, S., Zhang, C., and $\mathrm{He}, \mathrm{H}$. (2008). Complete oxidation of oxylene over $\mathrm{Pd} / \mathrm{Al}_{2} \mathrm{O}_{3}$ catalyst at low temperature. Catal. Today 139, 15-23. doi: 10.1016/j.cattod.2008. 08.020

Kim, H.-H., Ogata, A., and Futamura, S. (2008). Oxygen partial pressuredependent behavior of various catalysts for the total oxidation of VOCs using cycled system of adsorption and oxygen plasma. Appl. Catal. B Environ. 79, 356-367. doi: 10.1016/ j.apcatb.2007.10.038

Kroker, T., Kolb, T., Schenk, A., Krawczyk, K., Młotek, M., and Gericke, K.-H. (2012). Catalytic conversion of simulated biogas mixtures to synthesis gas in a fluidized bed reactor supported by a DBD. Plasma Chem. Plasma Process. 32, 565-682.

Leys, C., and Morent, R. (2012). "VOC removal from air by plasma-assisted catalysis: mechanisms, interactions between plasma and catalysts," in Plasma Chemistry and Catalysis in Gases and Liquids, eds V. I. Parvulescu, M. Magureanu, and P. Lukes (Weinheim: Wiley-VCH), 171-184.

Magureanu, M. (2012). "VOC removal from air by plasma-assisted catalysis - experimental work," in Plasma Chemistry and Catalysis in Gases and Liquids, eds V. I. Parvulescu, M. Magureanu, and P. Lukes (Weinheim: Wiley-VCH), 131-170.

Magureanu, M., Mandache, N. B., Elloy, P., Gaigneaux, E. M., and
Pârvulescu, V. I. (2005). Plasmaassisted catalysis for volatile organic compounds abatement. Appl. Catal. B Environ. 61, 12-20. doi: 10.1016/j. apcatb.2005.04.007

Magureanu, M., Mandache, N. B. Gaigneaux, E. M., Paun, C., and Pârvulescu, V. I. (2006). Toluene oxidation in a plasma-catalytic system. J. Appl. Phys. 99, 301-308. doi: 10.1063/1.2204353

Magureanu, M., Mandache, N. B., Parvulescu, V. I., Subrahmanyam, C., Renken, A., and Kiwi-Minsker L. (2007). Improved performance of non-thermal plasma reactor during decomposition of trichloroethylene: optimization of the reactor geometry and introduction of catalytic electrode. Appl. Catal. B Environ. 74, 270-277. doi: 10.1016/j.apcatb. 2007.02.019

Magureanu, M., Piroi, D., Mandache, N. B., Parvulescu, V. I., Parvulescu, V., Cojocaru, B., et al. (2011). In situ study of ozone and hybrid plasma $\mathrm{Ag}-\mathrm{Al}$ catalysts for the oxidation of toluene: evidence of the nature of the active sites. Appl. Catal. B Environ. 104, 84-90. doi: 10.1016/j.apcatb.2011. 02.025

Pârvulescu, V. I., Filoti, G., Pârvulescu, V., Grecu, N., Angelescu, E., and Nicolescu, I. V. (1994). Styrene hydrogenation on supported $\mathrm{Pd}$, $\mathrm{Fe}$ and $\mathrm{Pd}-\mathrm{Fe} / \gamma-\mathrm{Al} 2 \mathrm{O} 3$ catalysts. J. Mol. Catal. 89, 267-282. doi: 10.1016/0304-5102(93)E0312-5

Schmidt-Szałowski, K., Krawczyk, K., Sentek, J., Ulejczyk, B., Gorska, A., and Młotek, M. (2011). Hybrid plasma-catalytic systems for converting substances of high stability, greenhouse gases and VOC. Chem. Eng. Res. Des. 89, 2643-2651. doi 10.1016/i.cherd.2011.06.018

Van Durme, J., Dewulf, J., Demeestere, K., Leys, C., and Van Langenhove, H. (2009). Post-plasma catalytic technology for the removal of toluene from indoor air: Effect of humidity. Appl. Catal. $B$ Environ. 87, 78-83. doi: 10.1016/j.apcatb.2008.08.015

Van Durme, J., Dewulf, J., Leys, C., and Van Langenhove, H. (2008). Combining non-thermal plasma with heterogeneous catalysis in waste gas treatment: a review. Appl. Catal. B Environ. 78, 324-333. doi: 10.1016/j.apcatb.2007.09.035

Yamamoto, S., Yao, S., Kodama, S., Mine, C., and Fujioka, Y. (2009). Experimental study of SOF oxidation catalysts under plasma discharge condition. Chem. Lett. 38, 598-599. doi: $10.1246 / \mathrm{cl}$. 2009.598

Yang, Y.-C., Lee, B.-J., and Chun, Y.-N. (2009). Characteristics of methane reforming using gliding arc reactor. Energy 34, 172-177. doi: 10.1016/j.energy.2008.11.006

Zhang, H., Huang, Q., Ke, Z., Yang, L., Wang, X., and Yu, Z. (2012). Degradation of microcystin-LR in water by glow discharge plasma oxidation at the gase solution interface and its safety evaluation. Water Res. 46, 6554-6562. doi: 10.1016/j.watres.2012.09.041
Zhu, G., Han, J., Zemlyanov, D. Y., and Ribeiro, F. H. (2004). The turnover rate for the catalytic combustion of methane over palladium is not sensitive to the structure of the catalyst. J. Am. Chem. Soc 126, 9896-9897. doi: 10.1021/ ja049406s

Conflict of Interest Statement: The authors declare that the research was conducted in the absence of any commercial or financial relationships that could be construed as a potential conflict of interest.

Received: 05 April 2013; accepted: 04 June 2013; published online: 20 June 2013.

Citation: Magureanu $M$, Dobrin $D$, Mandache NB, Cojocaru B and Parvulescu VI (2013) Toluene oxidation by non-thermal plasma combined with palladium catalysts. Front. Chem. 1:7. doi: 10.3389/fchem.2013.00007

This article was submitted to Frontiers in Green and Environmental Chemistry, a specialty of Frontiers in Chemistry. Copyright () 2013 Magureanu, Dobrin, Mandache, Cojocaru and Parvulescu. This is an open-access article distributed under the terms of the Creative Commons Attribution License, which permits use, distribution and reproduction in other forums, provided the original authors and source are credited and subject to any copyright notices concerning any third-party graphics etc. 